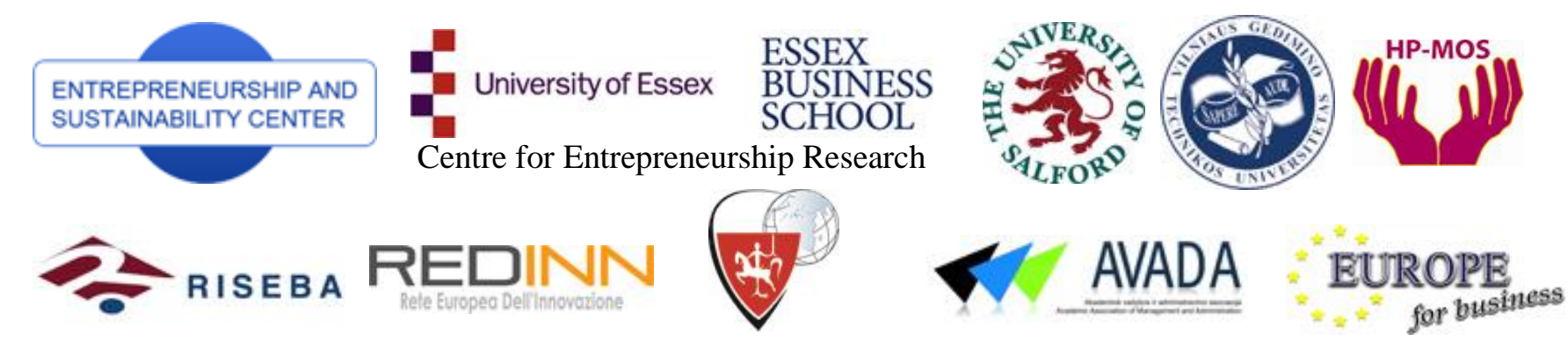

ENTREPRENEURSHIP AND SUSTAINABILITY ISSUES

ISSN 2345-0282 (online) http://jssidoi.org/jesi/aims-and-scope-of-research/

2013 Volume 1(2): 92-98

http://dx.doi.org/10.9770/jesi.2013.1.2(3)

\title{
ECONOMIC VIABILITY AND SUSTAINABILITY OF SOLIDARITY ECONOMY ENTERPRISES: A CASE STUDY ON THE TECHNOLOGICAL INCUBATOR OF POPULAR COOPERATIVES OF THE CATHOLIC UNIVERSITY OF SALVADOR
}

\author{
Lara Macedo de Alencar ${ }^{1}$, Helena Neves Almeida ${ }^{2}$ \\ ${ }^{1,2}$ University of Coimbra, Faculty of Psychology and Education Sciences, Coimbra, Portugal \\ E-mails: ${ }^{1}$ lara_alencar182@hotmail.com; ${ }^{2 h e l e n a . a l m e i d a @ f p c e . u c . p t ~}$
}

Received 25 September 2013; 3 accepted 30 November 2013

\begin{abstract}
The discussion about the social and solidarity economy, is gradually receiving more attention in the academic field. The main points of discussion are those related to the economic viability of this kind of enterprises and how is it possible to conceive a viable and sustainable management model that, at the same time, respects the peculiarities of this kind of organization. This paper presents the methodology applied by the ITCP UCSal (Technological Incubator of Popular Cooperatives of the Catholic University of Salvador) that acts in this field of economy since 2009 and which work has been recognized by the good results that it has been presetting.
\end{abstract}

Keywords: Social and solidarity economy; economic viability.

Reference to this paper should be made as follows: De Alencar, L.M.; Almeida, H.N. 2013. Economic viability and sustainability of solidarity economy enterprises: a case study on the technological incubator of popular cooperatives of the Catholic University of Salvador, Entrepreneurship and Sustainability Issues 1(2): 92-98.

http://dx.doi.org/10.9770/jesi.2013.1.2(3)

JEL classification: M2, M10

\section{Introduction}

The social and solidarity economy, that incorporates the popular sector economy, is gradually receiving more attention in the Brazilian academic and politic field, even more after the conception of the National Secretary of Solidarity Economy - SENAES in 2003. In some Brazilian regions, the economic reality demonstrates that the formal market does not have conditions to absorb the available manpower. As a result, it has created an informal market that incorporates in some regions a meaningful part of the population. That is the reality of the Salvador's Metropolitan Region (RMS), where, according to the IBGE (Brazilian Institute of Geography and Statics), in $2009,44 \%$ of the economically active population wasn't incorporated by the formal circuit if the economy. The solidarity economy tries to fill this gap by promoting through the self-employment, cooperatives, associations and the informal work that the sustenance of this meaningful part of the population could not, for different reasons, get in the formal work. Nonetheless, managing this kind of enterprises is special as they do not respond to the same rules as the capitalist companies and it is important to respect those differences. For example, the payment rules for those that participate of cooperatives are defined by the members of the cooperative (they can be paid by product produced, product sold, or by dividing the hole 
profit equally by all the employees), and it is completely different of the capitalist way of payment that pays for the manpower selling. For the solidarity economy there isn't a division between those that have the production means and those who have the manpower and this results in a joint and participative management often extremely complex.

The Technological Incubator of Popular Cooperatives of the Catholic University of Salvador (ITCP UCSal) works since 2009 with enterprises of this nature, trying to understand how they work and conceive a viable management that is applicable to the reality of the popular enterprises. It's a difficult mission as the rules that govern this other economy are different from those that rule the capitalism and, sometimes, the cost / benefit relation is ignored in order to consider others factors that directly interfere at the management of this enterprises such as friendship, family relations, and needs for extra business.

The work made by the ITCP UCSal resulted in a course for NGO's, incubators and governmental technicians, and for teachers and students that work in the solidarity economy field. The objective of this course is to discuss and present methods that can be applied to a viability study for popular enterprises. This course is based on the module "Economic Viability and Sustainability of solidarity economy enterprises" conceived by the ITCP itself and results in the capacitation of technicians that can disseminate this type of viability study.

Based on this module, we will discuss the methodology of intervention conceived, applied and developed by the ITCP. This methodology caught the attention of the government of Bahia's state and has been applied in two of their projects: Better life program (Programa Vida Melhor) and the capacitation of the technician of the public center of solidarity economy (A capacitação dos técnicos dos CentrosPúblicos de Economia Solidária).

\section{The popular sector economy}

Before analyzing the methodology mentioned above, it is important to clarify the economic context in which the ITCP acts so we can understand the complexity of the viability study developed by them. "By popular sector economy, understands the activities that has an economic rationality based in generating resources (monetary or not) designated to provide and replenish livelihood by using their own resources, aggregating, therefore, units of work instead of capital investment. This economy, of the popular sector, includes individual or familiar activities and also different modalities of associative work, formalized or not" (Kraychete 2012a).

Even though the popular sector economy is considered a collective way to generate resources, it does not have to incorporate the social sector. In other words, the popular sector economy identify a way to generate resources by which, even when the final objective is the income generation - without any political factor in it - the workers are driven to cooperate in order to have a better result. As an example of this kind of economy, the Professor Gabriel Kraychete (2012b) responsible for the ITCP UCSal, uses the case study of the familiar farmers that work producing fruit pulp. The author emphasizes that in this case the farmers already have the production equipment, and usually they produce and sell to the "atravesador" (name given to those that buy the farmers productions and sell to the final consumer or to some sale company). However, the farmers are stimulated to associate and transform their production into fruit pulp so they are able to sell the final product instead of the raw, as they are used to. In this case, the farmer's objective is to increase their family profit and if anything goes wrong they can always return to the raw production.

The example is useful to analyze the popular sector economy without the utopic label in which it is usually dressed by the researches of this economy. However, the activity does not have to be collective in order to be part of this economy. Another example is the housewives that produces and sell snacks. In this case, just like in the farmer's one, they already have the production equipment. Therefore, in this case it is important to notice that the production equipment are the same as the family consumer goods: stove, refrigerator, and household. In this context it is complicated to define some basic concepts such as annual depreciation, fixed production cost; variable production cost because it is not possible to separate the family and the enterprises belongs. Even though the society considers this type of workers as a problem to the economy, the reality is that the market it not able to formally absorb them as the neo-liberalism wants us to believe. We can validate 
this information through the data given by the IBGE (Brazilian Institute of Geography and Statistics) presented in the Table 1:

Table 1. Economically Active Population in the Salvador's Metropolitan Region

\begin{tabular}{|l|c|c|c|}
\hline \multicolumn{1}{|c|}{$\begin{array}{c}\text { Economically Active } \\
\text { Population }\end{array}$} & \multicolumn{3}{|c|}{ Year } \\
\cline { 2 - 4 } & $\mathbf{1 9 9 3}$ & $\mathbf{2 0 0 3}$ & $\mathbf{2 0 0 9}$ \\
\hline Informal Work & $41 \%$ & $44 \%$ & $44 \%$ \\
\hline Unemployed & $15 \%$ & $20 \%$ & $14 \%$ \\
\hline
\end{tabular}

Source: IBGE, PNAD (1993, 2003, 2009)

As we can verify in the table above, in this sixteen years with different government and economic and social politics, the tax of social exclusion from the formal market did not change meaningfully. This fact led us to believe that there is a limitation in the market to absorb the available hand labor. The popular sector economy brings a new solution to this problem, as Coraggio (1993), elucidates: "Enabling the emergence of a popular economy, from the substrate of economic activities whose agents are the manual and intellectual workers of country and city, whether dependent or independent, owners or non-owners. This approach does not idealize present-day popular values or practices, nor does it propose overcoming them with a view to attaining full capitalist modernity. It neither recommends disconnection from the capitalist market nor seeks full integration into it. It is an open proposal, inasmuch as it does not prefigure what specific activities, relationships and values are to constitute the popular economy in question. Nor does it choose between society and State, but rather proposes working at the interface between them."

In the European scenario, this movement can be compared to the cooperative movements of the $19^{\text {th }}$ Century, when they where lead to cooperate thought a treat of survival, as Chloupková (2002) explains: "Driven by this economic force for survival, by joining together farmers tend to achieve a greater bargaining strength, which is indeed one of the main reasons why they form cooperatives." (...) "Similarly, in many other European countries (Germany, France) the formation of cooperatives was also a response to threat imposed on farmers during industrialization. In Ireland the threat came from famine (1831), which has triggered the alternative mechanism of survival, i.e. cooperatives. 110 years later, the same kind of threat of survival was imposed on Spain, when the Basque country was in ruins as a result of civil war (1941). These external circumstances of threat of survival triggered the "alternative way/method" of survival, with the hope of prosperity, which resulted in the formation of cooperatives."

In fact, this popular economy can be understood as a result of the cooperative movement, although there are some essential differences. According to Jean-Louis Laville (2009), the movement toward a new economy resurges in the North hemisphere after the 80th. In the North it resurges through cooperatives, associations, proximity services, and it was an alternative to the injustices and the incapacity of the capitalist economy to present solutions. In the South hemisphere, they surges because of the same reason, but there is an ideological factor that differentiate both movements: they are trying to find a whole new economic system. This new economy, according to Coraggio (2010), must be "social (...) generate and enable other social relations, other relations with nature, other modes of reproduction, other options for life in society different from the capitalist paradigm of possessive individualism." This is what the ITCP believes and therefore targets the population that can help them achieve their main goal that is help to develop the studies about this new economy.

\section{Technological incubator of popular cooperatives of the Catholic University of Salvador (ITCP UCSal)}

Conceived in 2009, the ITCP is part of the extension program of the Catholic University of Salvador. It accessorizes popular enterprises, courses, workshops, seminars and researches. It was organized with the help from the Financier of Studies and Projects - FINEP (Ministry of Science and Technology), and from the Foundation for Research Support of the State of Bahia - FASESB. Institutionally the ITCO UCSal (2013) is part of the "Program popular sector economy" that has begun in the year 1998. This program, pioneer in the state of Bahia, accessorizes popular enterprises, courses, seminars, researches, and production of didactic material and publication of books and articles. The ITCP creation was a way to extend the action of the 
program. The ITCP UCSal works with enterprises of the popular sector economy that nationally are part of the solidarity economy. It acts actively in the Salvador's Metropolitan Region, although it also works with rural and urban popular enterprises in other regions of the state. The main objectives of the ITCP are:

1. To stimulate the development of economically viable and emancipatory ways of work through actions directed to the development and sustainability of the projects of popular solidarity economy.

2. Strengthen the initiative capacity of the popular economy organizations in the field of the necessary conditions to the economic viability and effective management of the developed enterprises.

3. Contributes to the production, improvement and amplification of the adequate technology instruments for the peculiar conditions of the popular sector economy enterprises.

4. Provide the academic studies complementation of students from different areas and evoke courses, monographs, and researches about the popular sector economy.

The accessory of the popular enterprises answers the ITCP three first objectives. The methodology used for the accessory received special attention for respect the peculiarities and limitations of this kind of organization. The main concern of the ITCP technicians is to ensure the autonomy of these organizations in order for them to work without the ITCP's intervention. It is only possible because the ITCP capacitates the technicians of the organizations. In order to capacitate these technicians, the ITPC developed a 32 hours course called "Economic viability and sustainability of solidarity economy enterprises" directed for technician of NOG'S, governmental organizations, teachers, students, and other technicians. Analyzing the didactic material used for this course - a book with texts and exercises-, we are able to describe the accessorize process.

The first part of the book (basic texts and complementary texts) manages to inform theoretically the technician producing a state of art. It is an important subject, because when you work with the popular sector, you are dealing with people that have low level of studies and could have never heard about the popular sector economy or solidarity economy. It is important to have this brief so they can see themselves as a movement and can learn about what have been done till the moment that can be used in their specific case. This first part of the book guides the first part of the accessory, which means that once that the organization is assisted by the ITCP, it tries to teach them about basic concepts that will be needed for the whole process. In this phase, they try to know the whole organization, using for it, active and participative methodologies: "One way to check and systematize knowledge about the activity of the enterprise is the members formulate for themselves a series of questions pertaining to all aspects of development: investments, work process, marketing and order management" Kraychete (2012b).

Based on the questions elaborated by the organizations representatives, it is possible to verify the knowledge level that they have about their own activity, because they usually do not know the answer for it. For example, in the case of the housewives that sell food, it is possible that they do not know the detailed recipe to produce the product they sell. Although, without this information, it is difficult to calculate the production cost. The questions should be about the following subjects:

A. What produce and in what quantity

The answer depends on the type of enterprises: if it is rural or urban, cooperative or familiar, if it sells to the final consumer or for another company. If the organization already exists, it will be easier to answer this question, on the other hand, it is useful to rethink about the possibilities to change some products or even stop producing some sort of products.

\section{B. Investment needs}

Inquires what materials are necessary for the enterprises to work, regardless of already existing or not. In those cases when the entrepreneurs already have the materials needed, this exercise is important for them to learn to separate what are production goods and consumer goods. It is also important to define what investments should be done in short and medium term and what are the depreciation value of equipment.

\section{Production process}

This subject inquires about the raw that will be used to produce all the products mentioned above. It is important to detail the production process because this information is necessary to calculate the production cost.

D. Sales process

This subject depends on the production process and on the quantity of production; because the commercialization process will be different considering the type of client which organization will be working with. One important point in this subject is the type of organization that we are working with. For example, if 
we are dealing with a cooperative, the remuneration procedure can be defined by the sales process instead of being defined by the production one. For this reason it is important to detail this process in order to avoid any future problem in the organization.

\section{E. Management and organizational process}

In this last subject, it is important to describe how the business is organized as structure and as administrative procedures. It is vital to define statutes, deciding if will exist a commission responsible for the association or cooperative; how this commission will be elected; for how long this commission will be responsible for the organization; and all others administrative rules. The control procedures should also be defined in this phase, as all the others related to the business administration.

The book has a list of questions that can help the technician in this first part of the accessory. In this list you can also find a part reserved to the accessory process. This part tries to understand what the organization expectative is when it comes to the intervention process and also tries to clarify what the ITCP is going to do.

The intervention process is cyclical and divided in three parts: the first phase is to formulate and answer questions about the organization. The ITCP technician asks the technicians of the organization to formulate and answer the questions and to bring them in the following session. In case that the questions are not enough or do not match the reality of the enterprises, they will do the exercise once more until the knowledge about the organization is enough to start making calculations about the activity.

The second phase of the accessory process is to make the viability calculations. In this phase are listed all the investment costs, production costs, depreciations costs, maintenance costs, and expect revenue. Based on these information's, the Contribution margin of sold product and break-even point are calculated. It is only possible to calculate it after having all the procedures defined, because the data used comes from those questions. The result from the break-even point will be compared with the expect revenue: if the break-even point is inferior then the expected revenue the enterprise is considered viable; if it is higher, they should think about solutions to make it viable. This process is done every time something changes in the administrative or productive procedures. It is important to remind that it is only possible to evaluate the viability of the enterprises by the break-even point, because all the peculiarities about the organization were listed in the first phase and all it costs were considered to calculate the break-even point. For this reason, the first phase of the accessory process should be detailed in order to avoid any mistake in the second phase.

The last phase in the accessory process is to archive the enterprises independence. The autonomy is achieved when the organization's technicians are able to elaborate the whole viability process by them, without any help from the ITPC. This independence results from repeat procedures in an organized and coherent way. This process is related to the skill development learned by participative and cooperative methodologies of questioning and answering, through a dialogic communication that empowers and creates synergy.

It is not the reproduction of the viability study and the calculation that develops the desired skills, but the ability to transform the ideas into questions and those into adequate answers according to the objectives. This relation between the possible and the desired constitutes a factor that enhances the knowledge appropriation and the quotidian reflection. It develops a prospective thought based on the initial idea but with possibilities to be developed. That is an aspect that cannot be neglected.

It is expected that the accessory process lasts for one year, although it can be extended. The first viability study is done by the ITCP based on the information received by the organization. After this one, the others are done by the organization's technicians that are helped by the ITCP technicians. Based on these studies, and helped by the ITCP technicians, the organization's technicians will try to find solutions for the enterprises' problems. For the organizations' technician empowerment, the ITCP provides the book mentioned in this article and an electronic material to help with the second phase. Once the process is over, the enterprises' technicians must be able to manage and change the organization whenever they have to, using for it the viability study appropriated by them.

\section{Conclusions}

Regarding the social aspects, the model is able to inspire synergy and the construction of social alternatives. It assumes that the empowerment - the development of their skills - has impact on the way that they see the 
future and results in an increase in power to make decisions Thompson (2007). It is about empowerment and for this reason, we discuss about rights strengthening and participation of groups, people and population susceptible to discrimination and exclusion. As Fazenda (2005) mentions: "this approach surpasses the paternalist temptation, of excessive protection and unilateral decisions [...], once that its objective is the autonomy of disadvantaged people and their participation on the same level as the technician, in a partnership approach."

In this context, the empowerment focused on the sustainability promotion of production initiatives, contributes to promote the construction of projects of life and hope needed to overcome crises. It increases the individual and collective power, with results in the life of families and individual, as on the context where they are integrate (Perkins and Zimmerman 1995). This synergy constitutes fundamental condition to the change. The individual has the perception of the opportunities and resources and acts despite the constraints and limitations. Although in less visible manner, and for this reason, less measurable, the individual and inter individual transformations resulting from the application of the model deserve equal prominence in the analysis.

For this reason, capacitating people from a questioning that has it genesis on a business idea or a productive activity reveals the potential to create alternatives with an important attitudinal component. The interaction provided by this methodology enables not only the construction and operationalization of abstract concepts, but also the discovery and affirmation of a process that has unknown complexity. Each formulated question implies a reflection process that overcomes the individual sphere when it is shared, and it develops trust, will, and the attitude to streamline resources that are initially indispensable: those that are part of the human being, because without it the work born may not be will not survive or progress. Thus, this integrative, holistic and adequate to the population needs approach, that often are stigmatized and vulnerable (Lee 2001; Adams 2008) implies the individuals strengthening focused on their autonomy, through the individuals capitalization (Faleiros 2002). The individual and collective self-esteem and self-confidence growth can be achieved through the (re)valorization and the incentive of people, families and community to develop their skills. In this context, it is important to rescue their culture, and traditional knowledge, (re)build their identity, increase their ability of manage resources that enable and empower their reproductive strategies, encourage people, families and community mobilization and organization, encourage their social dynamics inclusion, enlarge their access to organizations and social movements, and drive people, families and community to transform themselves into agents of their own development.

The model presented is pioneering and innovative and has been detached for considering the peculiarities of managing a solidarity economy organization, constituting itself a pedagogical and political process. This isolated factor is enough to understand all the attention that this model has received.

From the economic sight, although the model is recognized as effective and replicable in different places, it presents limitations. The two most important are the fact that it does not integrates a strategic dimension; this is to consider the procedural dynamics regarding the project's future objectives and does not foresee capital for reinvestments. Although it is understandable that it is not considered because this study is meant for a pour population, that survives or lives precariously, and so would not have conditions to reinvest in the organization, these aspects are extremely important to incentive procedures and continuous improvement.

Any organization is guided by its objectives, and for this reason planning would be useful to crate process and procedures that would help them to achieve their objectives. On the other hand, ignoring reinvest needs is naive, because they will have to change the equipments eventually and the depreciation will not be enough to cover it - it is necessary to purchase a better ones - and it is necessary to be ready for these situations.

This model has been selected by the Secretary of Work, Job, Income and Sports - SETREE - of the Bahia's state government to be adopted by their technicians of the Solidarity economy Public Center. It was foreseen to capacitate 135 technicians and agents of 9 Public Centers through the multipliers agents that will be capacitated during 2012 and 2013.

Another recognition was using this model as an inspiration for concept the Program Better Life - Urban (2013), also from the Bahia's state government. They used the ITCP's social technology to create indicators, operational instruments, didactic material and the methodology to capacitate the technicians. Those 
technicians will work in the Socioproductive Inclusion Units - UNIS, with the objective to include socioproductively 60.000 families by assisting enterprises of the popular sector economy.

\section{References}

Adams, R. 2008. Empowerment, participation and social work. BASW Practical Social Work. Series Editos, Jo Campling. 4th Edition. NY: Palgrave Macmillan.

Chloupková, J. 2002. European Cooperative Movement - Background and common denominators. Working paper, in Will postcommunist cooperatives work?: Social capital dynamics and the performance of cooperatives.

Coraggio, J.L. 1993. Promoting a popular economy: a path to Human development. Cap. XI CEAAL, Desarollo humano, economia popular y educacion 5: 5-6.

Coraggio, J.L. 2010. La Economia Social y Solidária como estratégia de desarollo en el contexto de la integración regional latinoamericana, in Revista de Economia Solidária, n.2. ACEESA, Dezembro.

Faleiros, V. 2002. Estratégias em Serviço Social. São Paulo, Cortez.

Fazenda, I. 2005. Empowerment e participação, uma estratégia de mudança. Centro Português de Investigação e História e Trabalho Social acedido. Available on the Internet: 〈http://www.cpihts.com/PDF/EMPOWERMENT.pdf〉.

IBGE, PNAD. 1993, 2003, 2009. Seminário Questões Contemporâneas, Salvador. Available on the Internet: < http://www.ibge.gov.br/english/>.

Kraychete, G. 2012a. Economia Popular Solidária: indicadores para a sustentabilidade. Comunicação apresentada no seminário Questões Contemporâneas, Salvador.

Kraychete, G. 2012b. Viabilidade econômica e sustentabilidade dos empreendimentos da economia solidária. Salvador - BA.

Laville, J.L 2009. A economia solidária: Um movimento internacional, Revista Crítica de Ciências Sociais 84 (Março): 7-47.

Lee, J. 2001. The Empowerment Approach to Social Work Practice. New York, Columbia University Press.

Perkins, D. D.; Zimmerman, M. A. 1995. Empowerment theory, research and application, American Journal of Community Psychology 23, 569-579.

Program Better Life. Secretaria de Desenvolvimento e Integração Regional. Programa Vida Melhor. 2013. Available on the Internet: <http://www.car.ba.gov.br/index.asp>.

Technological Incubator of Popular Cooperatives. 2013. Catholic University of Salvador. Extension and Community Action. Program and Projects. Presents information about the ITCP UCSsal. Available on the Internet: <http://www.ucsal.br>.

Thompson, N. 2007. Power and Empowerment.UK: Russel House Publishing.

Lara Macedo de Alencar, master from University of Coimbra, Faculty of Psychology and Education Sciences Coimbra, Portugal. Administrator with extensive experience in different areas of management, such as human resources, sales, logistics and project management and events.

Dr. Helena Neves Almeida is visiting professor and researcher at the Faculty of Psychology and Educational Sciences, University of Coimbra. Research interests: social work, social work education, international social work. 